\title{
Attitudes of Pregnant Women Regarding the Involvement of Medical Students in Prenatal Consultations at a University Hospital
}

\author{
Miriam da Silva Wanderley*, Dejano Tavares Sobral, Clarissa De Gasperi, Cybelle Lumara Alves de Oliveira, \\ Jamille Késsy Ferreira de Souza, Marcos Vinícius da Cruz Teodoro Carvalho and Paula Natsumi Yamazaki \\ Area of Gynecology and Obstetrics, University of Brasilia, Brazil
}

Submission: December 08, 2020; Published: December 14, 2020

*Corresponding author: Miriam da Silva Wanderley, Faculty of Medicine. The University of Brasilia, Brazil

\begin{abstract}
Objective: The study aimed to assess the willingness or unwillingness of pregnant women to accept medical students' attendance to prenatal consultations and test how these predispositions related to women's demographics, sensitivity to students' gender, and appraisal of prior experience with them.

Method: A questionnaire was used in interviews with patients awaiting a prenatal appointment at the Brasilia University Hospital, which included Likert-type questions about the women's motives to consent to or dissent from student attendance at the consultation and their appraisal of student interpersonal communication. Item-response frequencies and contingency analyses regarding the relationships between the women's demographics, motives, gender sensitivity, and appraisals were obtained.
\end{abstract}

Results: Among the 424 participants, 346 (81.6\%) were at ease with both male or female, 51 (12\%) only with women students, three (0.7\%) only with a male, and $24(5.7 \%)$ were uneasy with either male or female student attendance. Significant associations emerged between the participants' appraisal of students' interpersonal communication and reasons for consenting to their attendance $(p<0.001)$ and between their attitudes and the patients' comfort with their presence $(\mathrm{p}<0.05)$. Privacy issues and shame/fear of being attended by a student were the main dissenting motives, which related significantly $(\mathrm{p}<0.05)$ with gender sensitivity. No significant association emerged with demographic factors, except between women's parity and the receptivity to student attendance $(\mathrm{p}=0.035)$.

Conclusion: The participants expressed a broad acceptance of students' involvement in their consultations, regardless of gender. Prior experience of students' interpersonal communication eased the patients' receptivity to student involvement. A weak association emerged between patients' parity and receptivity.

Keywords: Gender; Medical students; Pregnancy; Prenatal; Attitude; Surveys and questionnaires; University hospital

\section{Introduction}

The contact of students with patients is vital for their medical training since, besides learning clinical skills, the trainees may likewise improve the interpersonal communication and professional relationships so essential to secure the future physician-patient partnership. However, patients' autonomy has been increasingly emphasized to define whether they accept students' attendance at their appointments and allow the learners to take part in performing clinical history and physical examination [1]. On that account, medical educators introduced simulators. But one cannot disagree with two arguments, as follows. First, teaching a pelvic exam (for example) in a plastic model is not the ideal or most suitable for students' training [2]. Second, paying standardized professional patients [3] could increase too much the cost and even make medical education unfeasible.

Patients in women's healthcare look more sensitive about student participation, given the peculiarities of the intimate and personal clinical history, and the delicate pelvic examination [1]. Work by Carmody et al. [4] showed that the acceptance of students decreases with increased intimacy in the consultation. Again, several studies have shown that the women's level of comfort with student attendance at consultation can vary according to sociodemographic, cultural, and educational factors, 
prior exposure to students, and the student's gender and level of involvement [3-8]. Prenatal care matters in a woman's life. It can give rise to her first contact with medical students, which may influence the decision to allow their participation in future stages of care, such as monitoring childbirth. To our knowledge, no earlier study has investigated the perceptions and appraisal of pregnant women about medical students' participation in prenatal consultations.

Therefore, this study aimed to assess the willingness or unwillingness of pregnant women to accept medical students' attendance to prenatal consultations and test how these predispositions relate to the women's demographics, their sensitivity to students' gender, and their appraisal of prior experience with them.

\section{Methods}

\section{Participants}

The study included women, at any gestational age, who were waiting for a scheduled appointment at the prenatal outpatient clinics of the University Hospital of Brasilia (HUB) from August 2018 to February 2019. All of them agreed to take part voluntarily and anonymously after receiving an explanation of the study objectives and conditions. No case was accepted of women who did not sign the Free and Informed Consent Form (over 18 years old) or the Free and Informed Assent Form (under 18 years old). Trained medical students interviewed the patients using a structured questionnaire based on a literature review [4,6,9-11]. The Human Research Ethics Committee of the Faculty of Medicine approved the study (approval 1,126,648; CAAE 05670919.9.0000.5558).

\section{Procedures}

Five-point Likert scales were used to register the women's responses in questions about reasons for willingness or unwillingness to accept students during the obstetric interview and physical/pelvic examination, and regarding their appraisal of the learners' interpersonal communication skills. The answer to a pivotal question about the participant's stance of comfort on the student's involvement in the consultation was recorded as follows: $0=$ uneasy with male or female, $1=$ at ease only with a female, $2=$ at ease with both male and female students.

We defined a composite variable by dichotomizing and adding the responses related to three ways of receptivity: comfort with student presence $(1=$ at ease with either a male or female student), the number of students allowed in the consultation (1= three or more students), and acceptance of pelvic examination by a student ( $1=$ acceptance, either by a male or female student). The index values ranged from zero to three.

\section{Analysis}

Contingency analyses, using the SPSS software version 17, included the factors above and selected either Cramer V, Kendall tau-b, or Spearman rho tests as measures of association. The adopted statistical significance value was $\mathrm{p}<0.05$.

\section{Result}

A total of 425 pregnant women were interviewed, but we excluded one case with incomplete data from analysis. The participants had a mean age of 30.31 years old (SD 7.17), ranging from 13 to 54 years. Most of them (75.2\%) were in a stable marital relationship, $53.3 \%$ had one to two children, while $33.7 \%$ were nulliparous. About $62 \%$ of the participants reported no more than high school education, and $55.7 \%$ of them earned a monthly family income between one to two minimum wages.

Just $19.3 \%$ of the pregnant women were waiting for their first prenatal consultation at the HUB, while 54.3\% reported they had one to five prior consultations, and $26.4 \%$ reported six or more prior appointments. When asked about medical students' involvement (at the HUB), 85.6\% of the patients said they knew that students could take part in the appointment, $73.1 \%$ reported prior attendance by students. Among the 424 participants, $81.6 \%$ admitted being at ease with both male or female, $12 \%$ only with a female, $0.7 \%$ only with a male, and $5.7 \%$ were uneasy with either male or female student attendance. $44.5 \%$ said that three or more attending students would be acceptable in a clinical appointment, On student's involvement in the consultation, 90.8\% of the participants reported that they would allow both male and female students to collect their medical history, while $6.4 \%$ would grant permission only for female students. In comparison, $68.9 \%$ of the patients would allow the pelvic examination by either male or female students, while $19.1 \%$ would only let the examination by female students. Noticeably, $87.3 \%$ of the participants did not have a gender preference over their Ob-Gyn, while just $11.8 \%$ preferred a female Ob-Gyn in the consultation.

Concerning the women's reasons to dissent from student's attendance at the consultations, most of the patients expressed wanting privacy during the gynecological exam (52.4\%), followed by believing that the appointment takes longer if the student is present $(46.7 \%)$, wanting privacy during the clinical history (37\%), and fear or shame of being examined by a male student (35.4\%). Patients uneasy with male student attendance $(\mathrm{N}=51)$, in contrast with patients at ease with male or female presence $(\mathrm{N}=346)$, were more likely to agree with reasons to dissent from learner's participation in consultations.

(Table 1 placed about here.) Patients with prior experience expressed that $77.6 \%$ of the students asked for permission to take part in the consultation. They also agreed that $97.6 \%$ of students treated them with respect, $94.3 \%$ showed attention to what they reported and concern about their health status, 97.9\% maintained a professional attitude during the consultation, $95.5 \%$ communicated well, and $97.6 \%$ showed respectful manners and good looks. Notably, all the cited interpersonal communication skills showed significant associations with three stances of patients' comfort. Table 2 shows the data.

Table 1: Measures of association (Kendall's tau-b) between patients 
stance of comfort with and without male student attendance ${ }^{*}$ and rank of agreement ${ }^{* *}$ with their reasons to dissent from the learners' attendance at prenatal consultations $(\mathrm{N}=397)$.

\begin{tabular}{|c|c|c|}
\hline \multirow{2}{*}{ Reasons for Dissenting to Student Attendance } & \multicolumn{2}{|c|}{ Stance of Comfort } \\
\cline { 2 - 3 } & 0.358 & \multicolumn{2}{|c|}{ Tau-B } \\
\hline Being afraid or ashamed of being examined by a male student & 0.208 & 0.184 \\
\hline Wanting privacy during the gynecological exam & 0.182 & $<0.001$ \\
\hline Feeling insecure or uncomfortable with the student's presence & 0.163 & $<0.001$ \\
\hline Wanting privacy during clinical history & 0.001 \\
\hline Believing that the student hinders the consultation & 0.154 & 0.001 \\
\hline Believing that only the doctor is prepared for care & 0.084 & 0.001 \\
\hline Being afraid or ashamed of being examined by a female student & 0.026 & 0.082 \\
\hline Believing that the consultation takes longer if the student is present & 0.012 & 0.578 \\
\hline Suspicious of student-given guidance & & 0.807 \\
\hline
\end{tabular}

*At ease with male or female $=0(n=346) ;$ At ease only with female $=1(n=51)$.

** $5=$ total agreement, $1=$ total disagreement (with expressed reason).

Table 2: Measures of association between the patients' stance of comfort ${ }^{\star}$ at the expectation of consultation and their appraisal ${ }^{\star *}$ of medical students' interpersonal communication in prior appointments $(\mathrm{N}=332)$.

\begin{tabular}{|c|c|c|}
\hline Students' Interpersonal Communication & Kendall's tau-b & Ptance of Comfort \\
\hline She/He: & 0.187 & 0.001 \\
\hline Conducted the consultation professionally & 0.171 & 0.001 \\
\hline Asked permission to attend the consultation & 0.168 & 0.002 \\
\hline Attended with attention and respect & 0.160 & 0.002 \\
\hline Showed care for my health & 0.136 & 0.010 \\
\hline Maintained good communication during the consultation & 0.108 & 0.043 \\
\hline Had respectful manners and good looks & & \multicolumn{2}{|c|}{} \\
\hline
\end{tabular}

${ }^{*} 0=$ uneasy with either male or female student, $1=$ at ease only with a female, $2=$ at ease with either male or female students.

** $5=$ total agreement, $1=$ total disagreement (with expressed attribute).

(Table 2 placed about here.) Over $80 \%$ of participants agreed with each of the following reasons for consenting to medical student participation: wishing to contribute to the training of future doctors (96.3\%), learning about health when the doctor teaches the student (93.4\%), believing that students' participation in gynecological consultations import (90.8\%), feeling that their presence helps with medical care (89.9\%), expecting their involvement in medical consultations at the HUB (89.6\%), feeling good about their presence at the appointments (89.2\%) and being confident about the medical students' capacity (80.4\%).

Significant associations emerged between each of the seven reasons to consent learner's attendance in future consultations and an overall score of the patients' appraisal of student interpersonal communication skills in prior appointments. Table 3 shows the association between the participants' reasons for consenting and the overall score of their appraisal of the students' communication attributes. (Table 3 placed about here.) A significant association $(\mathrm{p}<0.001)$ emerged between the acceptable number of attending students in consultations, according to the patients, and each reason for the women to consent to their attendance (as listed in Table 3). The effect sizes of the correlations (as measured by Spearman's rho) ranged from 0.197 (Learning about her health when the teacher is teaching the student) to 0.350 (Feeling good about the student attendance at the consultation). 
Table 3: Correlation coefficients between the women's reasons to consent to the participation of medical students in prenatal consultations and the overall rating of their appraisal of students' interpersonal communication skills in prior consultations $(\mathrm{N}=335)$.

\begin{tabular}{|c|c|c|}
\hline \multirow{2}{*}{ Reasons for Consenting to Student Participation: } & \multicolumn{2}{|c|}{ Interpersonal Communication } \\
\hline & Spearman's Rho & $\mathbf{P}$ \\
\hline Believing that student participation in consultations helps medical care. & 0.333 & $<0.001$ \\
\hline Feeling good about the student attendance at the consultation. & 0.305 & $<0.001$ \\
\hline Trusting the capacity of local medical students. & 0.305 & $<0.001$ \\
\hline Wanting to contribute to the training of future doctors. & 0.293 & $<0.001$ \\
\hline Expecting student participation in medical appointments at the HUB. & 0.263 & $<0.001$ \\
\hline Learning about her health when the teacher is teaching the student. & 0.248 & $<0.001$ \\
\hline Believing that it is important that medical students participate in gynecological consultations. & 0.230 & $<0.001$ \\
\hline
\end{tabular}

Regarding how the pregnant women perceived the right to refuse student participation, $42 \%$ considered that they could refuse this participation, $21.2 \%$ vented uncertainty whether they might decline, and $36.8 \%$ felt that they could not refuse students at the consultation. No significant association emerged between the patients' perception of the right of refusal and any of their demographics (as gauged by Cramer's V tests). Finally, concerning demographic factors, the sole statistically significant association was between the participants' parity and their index of receptivity to students' attendance to prenatal consultations (Cramer V = $0.135, \mathrm{p}=0.035$ ).

\section{Discussion}

Gaining skills and abilities is fundamental for medical students' education. Ethical principles that govern interactions with patients must balance it [12]. Oddly, more than half of the participants in our study did not know or expect that they could refuse the student's presence. The university hospital setting may contribute to that perception because most participants knew that students could participate in their consultation. However, the eventual learners' attendance should not become an imposition to accept them. Anyhow, 77.6\% of the students asked for permission to be present at the prenatal consultations, a better finding than in some other studies $[2,8]$.

Several studies have shown that women's satisfactory experiences with student attendance usually allow greater student involvement in later consultations $[1,5,13,14]$. In our work, over $70 \%$ of the patients had been attended by students, and of those, over $80 \%$ felt comfortable with the learners' presence in their prenatal consultations, a higher percentage than that observed by Hartz et al. [14] Further to familiarity with students, the number of attending students was also found to be relevant for the comfort of patients. Over two-thirds of the interviewees agreed to accept up to three attending students. While $90 \%$ of patients would allow students of both sexes to get their medical history, only $68.9 \%$ would allow physical examination by the same students. These figures are compatible with the findings of a comprehensive review [15], which assessed the acceptance of medical students by general practice patients.

Most participants in our study thought students help with medical care and had friendly feelings with their presence. Thus, it is intriguing that above $40 \%$ of the respondents indicated that the delay in the consultation was a reason for unwillingness to consent the student attendance (although a good many of them felt that the delay eased communication and the doctor devoted them more time than usual). Remarkably, the patients' most favorable reasons to consent to the learners' attendance at the consultation were wishing to contribute to the education of future doctors and learning more about their health (while listening to the teacher's explanations to students). These findings point out the mutual benefits engendered in the situation and are like those of several other studies $[6,9,11,14,16]$.

We found that most pregnant women accepted both male and female students, as in other studies $[8,13,16]$ However, for the minority that expressed a gender reservation, the preference for women was 17 times greater than the preference for males. Noticeably, gender restriction was significantly associated with the patients' motives for dissenting from students' participation in consultations. Issues such as a wish for privacy, shame, or fear of being examined by students were the critical reasons for unwillingness regarding their attendance, as observed in other studies $[6,9,17]$. We reported similar findings in a previous study of gynecological consultation carried out at the same educational institution [8]. The gender sensitivity issue may be related to the decreasing demand for a residency in Ob-Gyn by male student [18-20]. Male students have less exposure to practical activities and procedures and suffer more refusal to take part in women's care during graduation [7,21-23]. The feeling that their gender has put them at a disadvantage in acquiring skills and competences could harm their future career choice and professional practice in Ob-Gyn.

Coppola et al. [21,22] showed that patients were more accepting of the pelvic exam by a male student when attended by 
a male physician. From an educational point of view, their findings would support the need for more male graduates to embrace the career of gynecology and obstetrics. On this account, Higham and Steer [24] observed that more significant clinical experience occurred when the teacher, the student, and the patient belonged to the same sex.

Physician gender is not a primary concern for most patients $[9,13]$. In our study, almost $90 \%$ of patients had no gender preference about the attending Ob-Gyn. A systematic review pointed out that other factors such as experience, communication skills, clinical competence are essential when choosing an obstetrician-gynecologist [25]. Thus, teachers and doctors who work with students in practical activities in Ob-Gyn should encourage student acceptance, regardless of gender, by the patients. The professional involvement in gender equity should assure that practical learning experiences are similar between genders and thereby increase the male student interest in an $\mathrm{Ob}$ Gyn career $[23,26]$.

As for sociodemographic factors, statistical significance emerged only between parity and receptivity to students. Different results in the literature regarding these factors have shown that generalizations cannot be made between them and students' involvement $[4,6,9,18]$ In the study by Nicum and Karoo [27], the patients' age and social class did not correlate with the acceptance of students at childbirth time, but the primiparous women were the least willing to accept them.

This work has the limitations of a questionnaire-based crosssectional study carried out in a single public institution in a unique Brazilian city. Still, medical students acting as interviewers might bias the patients' responses. However, one must highlight the obstetric patients' wide acceptance of student participation in their prenatal appointments and the fact that no woman refused a learner's presence in the actual consultation. As far as we know, this Brazilian study is the first to assess such an educational perspective in an obstetrics clinic. Teachers and doctors should act to upgrade the educational opportunities of every student by improving the learners' professional, cognitive, and humanistic skills, thus contributing to refining their future doctor-patient relationship and eventual career choice.

\section{Conclusion}

Women in prenatal care expressed a generous acceptance of students' participation in their consultations, regardless of gender. Prior experience of student attendance eased the patients' receptivity to learner's involvement, as highlighted by the positive association of comfort level with the appraisal of students' communication skills. Being afraid or ashamed of being examined by a male student was the most decisive reason for dissenting from student attendance. A weak association emerged between women's parity and receptivity to student involvement.

\section{References}

1. Anfinan N, Alghunaim N, Boker A, Hussain A, Almarstani A, et al. (2014) Obstetric and gynecologic patients' attitudes and perceptions toward medical students in Saudi Arabia. Oman Med J 29(2): 106-109.

2. Ikeako LC, Adiuku-Brown A, Ezgwui HU, Onuh AC, Okeke TC, et al. (2016) Attitudes of patients to medical students in the gynaecology clinic: a Nigerian experience. Br J Med \& Medical Research 15(11): $1-10$.

3. Siwe K, Wijma K, Stjernquist M, Wijma B (2007) Medical students learning the pelvic examination: comparison of outcome in terms of skills between a professional patient and a clinical patient model. Patient Educ Couns 68(3): 211-217.

4. Carmody D, Tregonning A, Nathan E, Newnham JP (2011) Patient perceptions of medical students' involvement in their obstetrics and gynaecology care. Aus N Zee J Obstet Gyn 51(6): 553-558.

5. Rizk DEE, Al-Shebah A, El-Zubeir MA, Thomas LB, Hassan MY, et al. (2002) Women's perceptions of and experiences with medical student involvement in outpatient obstetric and gynecologic care in the United Arab Emirates. Am J Obstet Gynecol 187(4): 1091-1100.

6. Subki AH, Algethami MR, Addas FA, Alnefaie MN, Hindi MM, et al. (2018) Women's perception and attitude to medical students' participation in obstetrics and gynecology care. Saudi Med J 39(9): 902-909.

7. Kostov S, Koppula S, Babenko O (2018) Gender differences in women's health and maternity care training: A scoping review. MedEdPublish, Scotland.

8. Wanderley MS, Sobral DT, Lima BAO, Freire MEB, Silva MAC, et al. (2019) Attitudes and personal attributes regarding patient receptivity towards the participation of medical students in gynecological consultations: a cross-sectional study. Rev Bras Ginecol Obstet 41(10): 613-620.

9. Ching SL, Gates EA, Robertson PA (2000) Factors influencing obstetric and gynecologic patients' decisions toward medical student involvement in the outpatient setting. Am J Obstet Gynecol 182(6): $1429-1432$.

10. Alawad AAM, Younis FH (2014) Patients' Attitude towards Undergraduate Medical Students at University Charity Teaching Hospital in Sudan. Int J Med (Dubai) 2(1): 28-31.

11. Berry RE Jr, O'Dell K, Meyer BA, Purwono U (2003) Obtaining patient permission for student participation in obstetric-gynecologic outpatient visits: a randomized controlled trial. Am J Obstet Gynecol 189(3): 634-638.

12. Akkad A, Bonas S, Stark P (2008) Gender differences in final year medical students' experience of teaching of intimate examinations: a questionnaire study. BJOG 115(5): 625-632.

13. Mavis B, Valenok P, Schuh R, Marshall J, Jeffs MC, et al. (2006) Medical students' involvement in outpatient clinical encounters: a survey of patients and their obstetricians-gynecologists. Acad Med 81(3): 290296.

14. Hartz MB, Beal JR (2000) Patients' attitudes and comfort levels regarding medical students' involvement in Obstetrics-Gynecology outpatient clinics. Acad Med 75(10): 1010-1014.

15. Mol SS, Peelen JH, Kuyvenhoven MM (2011) Patients' views on student participation in general practice consultations: a comprehensive review. Med Teach 33(7): e397-e400.

16. Johnson AM, Schnatz PF, Kelsey AM, Ohannessian CM (2005) Do women prefer care from female or male obstetrician-gynecologists? A study of patient gender preference. J Am Osteopath Assoc 105(8): 369-379. 
17. Grasby D, Quinlivan JA (2001) Attitudes of patients towards the involvement of medical students in their intrapartum obstetric care. Aust N Z J Obstet Gynaecol 41(1): 91-96.

18. Gerber SE, LoSasso AT (2006) The evolving gender gap in general obstetrics and gynecology. Am J Obstet Gynecol 195(5): 1427-1430.

19. Lambert EM, Holmboe ES (2005) The relationship between specialty choice and gender of U.S. medical students, 1990-2003. Acad Med 80(9): 797-802.

20. Wanderley MS, Sobral DT (2017) Ob-Gyn gender preferences of gynecology ambulatory patients and students' choice of the specialty. Rev Bras Ginecol Obstet 39(12): 645-646.

21. Coppola LM, Reed KL, Herbert WN (2014) Comparison of patient attitudes and provider perceptions regarding medical student involvement in obstetric/gynecologic care. Teach Learn Med 26(3): 239-243.

22. Zahid AZM, Ismail Z, Abdullah B, Daud S (2015) Gender bias in training of medical students in obstetrics and gynaecology: A myth or reality? Eur J Obstet Gynecol Reprod Biol 186: 17-21.
23. Chang JC, Odrobina MR, McIntyre-Seltman K (2010) The effect of student gender on the obstetrics and gynecology clerkship experience. J Womens Health (Larchmt) 19(1): 87e92.

24. Higham J, Steer PJ (2004) Gender gap in undergraduate experience and performance in obstetrics and gynaecology: Analysis of clinical experience logs. BMJ 328(7432): 142-143.

25. Janssen SM, Lagro-Janssen ALM (2012) Physician's gender, communication style, patient preferences and patient satisfaction in gynecology and obstetrics: a systematic review. Patient Educ Couns 89(2): 221-226.

26. Craig LTB, Buery-Joyner SD, Bliss S, Everett EN, Forstein DA, et al. (2018) To the Point: Gender differences in the obstetrics and gynecology clerkship. Am J Obstet Gynecol 219(5): 430-435.

27. Nicum R, Karoo R (1998) Expectations and opinions of pregnant women about medical students being involved in care at the time of delivery. Med Educ 32(3): 320-324.

\section{Your next submission with Juniper Publishers will reach you the below assets}

- Quality Editorial service

- Swift Peer Review

- Reprints availability

- E-prints Service

- Manuscript Podcast for convenient understanding

- Global attainment for your research

- Manuscript accessibility in different formats

( Pdf, E-pub, Full Tsext, Audio)

- Unceasing customer service

Track the below URL for one-step submission

https://juniperpublishers.com/online-submission.php 